\title{
Determinants and Knowledge on Geo-Helminthiasis in Prison Inmates: Case of Kassapa Central Prison, Lubumbashi, Democratic Republic of Congo
}

\author{
André Ngombe Kaseba ${ }^{1 *}$, Tshipapa Mujinga², Aly Antoine Kamano ${ }^{3}$, Cissé Kadari ${ }^{4}$, \\ Kikunda Ghislain ${ }^{2}$, Nowa Mutangala ${ }^{5}$, Philippe Mulenga-Cilundika², Eric Mukomena Sompwe ${ }^{2}$ \\ ${ }^{1}$ School of Public Health, University of Lubumbashi, Lubumbashi, Democratic Republic of Congo \\ ${ }^{2}$ Faculty of Medicine, University of Lubumbashi, Lubumbashi, Democratic Republic of Congo \\ ${ }^{3}$ Ministry of Health, Conakry, Republic of Guinea \\ ${ }^{4}$ Health Science Research Institute, Ouagadougou, Burkina Faso \\ ${ }^{5}$ Ruashi Mining, Lubumbashi, Democratic Republic of Congo \\ Email: ^andrekaseba86@gmail.com
}

How to cite this paper: Kaseba, A.N., Mujinga, T., Kamano, A.A., Kadari, C., Ghislain, K., Mutangala, N., Mulenga-Cilundika, P. and Sompwe, E.M. (2021) Determinants and Knowledge on Geo-Helminthiasis in Prison Inmates: Case of Kassapa Central Prison, Lubumbashi, Democratic Republic of Congo. Health, 13, 600-618.

https://doi.org/10.4236/health.2021.135045

Received: March 9, 2021

Accepted: May 23, 2021

Published: May 26, 2021

Copyright $\odot 2021$ by author(s) and Scientific Research Publishing Inc. This work is licensed under the Creative Commons Attribution-NonCommercial International License (CC BY-NC 4.0). http://creativecommons.org/licenses/by-nc/4.0/ (c) (i) (8) Open Access

\begin{abstract}
Introduction: Geohelminths are infections due to various species of parasitic worms transmitted by eggs present in human excreta which contaminate the soil where sanitation is poor. The objective of this study was to analyse the determinants and knowledge on geo-helminthiasis among inmates and care providers in the Kassapa prison environment in Lubumbashi in the Demographic Republic of Congo. Methods: This is a cross-sectional descriptive study which was conducted from September 21 to October 15, 2020 in Kassapa prison in Demographic Republic of Congo. Estimates of the prevalence and general characteristics of geo-helminthiasis in prisoners were calculated by descriptive analyses. The analysis of determinants was performed based on a binary logistic regression. Results: With regard to the quantitative section, the study used a sample size of 1083 while a sample size of six was considered for the qualitative section. The annual prevalence of geo-helminthiasis was $10.2 \%, 4.8 \%$ and $2.9 \%$ respectively for 2017, 2018 and 2019. It was found that the general prevalence of geo-helminthiases was $17.9 \%$. The age group above 39 years constitutes the modal class with $29.4 \%$, the least affected age group being that of minors with $6.3 \%$. The association is statistically significant between sex, treatment, prison residence and year. Thus, taking gender into account, women are by $2.3(\mathrm{OR}=2.3,95 \%$ CI $[1.3 \% ; 4.8 \%]$, $\mathrm{p}$ value $<0.05)$ more likely to be at risk of suffering from geo-helminthiasis than men, and mebendazole is by 2.1 a better treatment of geo-helminthiasis than albenda-
\end{abstract}


zole $(\mathrm{OR}=2.1,95 \%$ CI $[1.1 \% ; 4.6 \%]$, p-value $<0.05)$. Transmission routes of geo-helminthiasis are relatively well known among these actors who have often reported eating dirty food, walking barefoot, and drinking dirty water. Conclusion: This descriptive cross-sectional study rounds off by pointing to poor hygiene, insufficient health education and a low socio-economic level exposing inmates to the risk of contracting geo-helminthiasis, particularly as prisoners in Kassapa live in a difficult situation and are therefore very vulnerable.

\section{Keywords}

Determinants, Knowledge, Geo-Helminthiasis, Prison Environment, DRC

\section{Introduction}

Geohelminths are infections due to various species of parasitic worms transmitted by eggs present in human excreta which contaminate the soil where sanitation is poor. Around 39 million perfectly healthy people have lost their lives due to geo-helminthiasis infections [1] [2]. These worms affect the poorest and the most destitute of the population. Helminthiases and intestinal worms are parasitic diseases which are widely spread throughout the world, particularly in tropical and inter-tropical regions [1]. Today, the detainee can avail himself of a certain number of fundamental rights provided for by international and national texts [3]. These include the right to family life, the right to health, freedom of religion and the right to vote [3]. In order to respond to the worrying health situation in prisons, the law of 18 January 1994 relating to public health and social protection [3] was enacted. This law, the objective of which was to offer prisoners quality and sustained healthcare that compares with the one provided to the population as a whole, entrusted hospitals with the mission of ensuring preventive and curative care to prisoners [3]. As a result, each prison has a health unit, which depends on the local hospital. According to the World Health Organization (WHO) 2000 report, around 1.5 billion people were infected with geo-helminthiasis worldwide [4]. Intestinal helminths affect around $10 \%$ of the population in resource-limited countries [4]. The number of annual death rate directly linked to geo-helminthiasis has reached 135.000 worldwide, but the main impact of these infections lies in the chronic effects on health and nutrition [5].

Geohelminths (soil-transmitted helminths) affect the poorest and the most destitute of the population. Helminthiases and intestinal worms are parasitoses that are widely spread across the world, more particularly in tropical and intertropical regions. [4] [6]. The estimated number of preschool children in need of chemo-prevention increased from 273.1 million in 2017 to 310.5 million in 2018; and for school-age children, it rose from 596.8 million to 762.4 million [7]. This increase by $23 \%$ in the denominator has had an impact on global coverage and on progress towards meeting the WHO 2020 target [7], which is to treat at least 
$75 \%$ of preschool and school-age children in all countries experiencing endemic geo-helminthiasis [7].

A study carried out in 2005 by the National Nutrition Program in the DRC revealed an average prevalence rate of $82 \%$ in children aged 1 to 5 in all provinces [8]. The annual death rate linked to geohelminths as infections has reached 135,000 , but the main impact of these infections is their chronic effects on health and nutrition [5]. An understanding of determinants of geo-helminthiasis can be gained from, among other things, the precarious living and hygiene conditions prevailing in the prison environment as these are associated with geohelminths. Transmission is by ingestion or by transdermal penetration [6] [9]. Water and food as well as hygienic conditions play a major role in transmission. Worthy of note are drinking water, hands and raw vegetables soiled by embryonated eggs (dirty hand disease) [1] [10].

One of the strengths of this study was our focus on analyzing the determinants and knowledge on geo-helminthiasis among inmates in the Kassapa prison environment in Lubumbashi in the DRC, a country in central Africa where geo-helminthiasis is a major public health problem. To address this gap, it seemed appropriate for us to carry out an analysis of these infections among prisoners.

The objectives of the study were to: determine the prevalence of geo-helminthiasis, analyze the determinants of such infections among inmates in the prison environment.

\section{Patients and Methods}

\subsection{Type and Framework of Study}

This is a cross-sectional descriptive study carried out in Lubumbashi prison in the DRC.

\subsection{Study Population}

The study population primarily consists of inmates of Kassapa central prison in Lubumbashi, whose information was accessed through medical consultation and laboratory forms and subsequently from health care providers.

\subsection{Understanding the Data Source}

Consultation, and laboratory forms, nursing staff and prisoners were used as sources of data on this study. It was carried out from September 21 to October 15, 2020 in Kassapa prison and aimed at analysing the determinants of geo-helminthiasis in prisoners and describing connections with other factors accounting for the increased incidence of such an infection as a health problem. We first analysed the local health situation in the DRC, using a conceptual framework inspired by the health system [11]. On being granted international sovereignty, the DRC inherited a health system that was mainly reliant on hospitals and clinics supported by mobile teams to fight major endemics [11]. 


\subsection{Sample Size}

With regard to the quantitative approach, only detainees who had been registered during the time-span of the study were included, that is 1083 (Figure 1: flow diagram), with the following inclusion and exclusion criteria:

Inclusion criteria: being detained and registered during the time-span of the study.

Exclusion criteria: lack of data on medical consultations.

On the other hand, the qualitative approach included the following criteria: being a care provider working at the prison health center, being a prisoner during the six months preceding our survey and having given verbal and written consent to participate in the study after having learned about the objectives and expected results of the study.

We carried out a reasoned choice sampling of Six (6) participants who were distributed as follows: three (3) from care providers and three (3) others from prisoners of Kassapa. The following were inclusion Criteria: Being a care provider working at the prison health center, being a prisoner during the six months preceding our survey and having given verbal and written consent to participate in the study after having learned about the objectives and expected results of the study. Exclsuion criteria included: Refusal to participate in the study and or to sign the consent form regardless of the reason for refusal, to be a nursing staff and not to have worked for a year in the post.

\subsection{Statistical Analysis}

The data collected was entered with the Excel software before being exported into the Stata 16.1 software. Then, we cleaned up our database before proceeding with the analysis. The semi-structured interviews were transcribed on world,

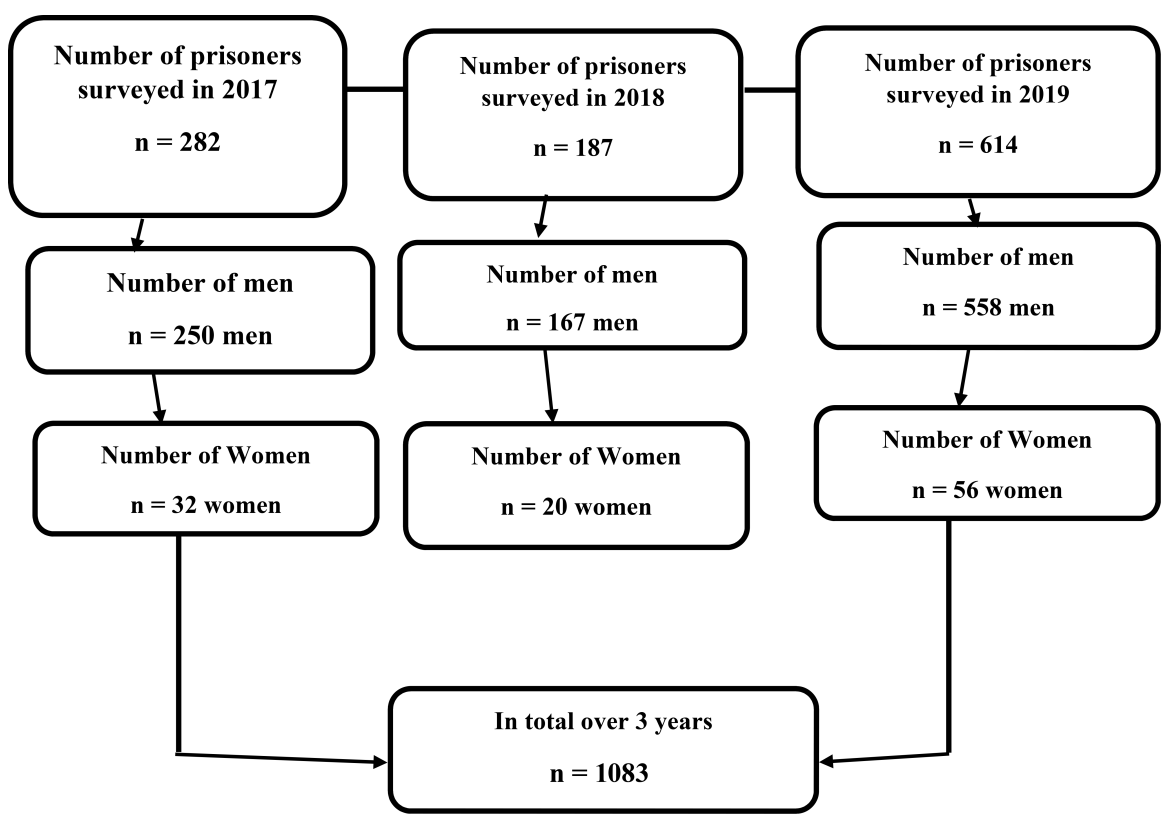

Figure 1. Flow diagram. 
then cleaned up. Finally, we exported transcribed data into QDA Miner Lite software to carry out analyses. In actual fact the qualitative approach involved conducting a horizontal and vertical thematic analysis. Our study used the following dependent variable: Geo-helminthiasis defined as: 0 "Absence of geo-helminthiasis"; 1 "Presence of geo-helminthiasis". Contextual variables included clinical and paraclinical variables, for instance reasons for consultations. Paraclinical variable included such elements as macroscopic and microscopic examinations, biology. Finally, sociodemographic Variables that were used included Gender, age, commune of origin in addition to such individual variables as knowledge about geo-helminthiasis, the systematic screening of geohelminths, hygiene and sanitation practices.

\section{Results}

\subsection{Prevalence of Geo-Helminthiasis}

The annual prevalence of geo-helminthiasis was $10.2 \%$; $4.8 \%$ and $2.9 \%$ respectively for 2017, 2018 and 2019. It was noted that the general prevalence of geohelminthiases was $17.9 \%$. Lubumbashi and Ruashi as communes of origin were more prevalent with $8.2 \%$ and $7.1 \%$ respectively as shown below in Table 1 .

\subsection{Sociodemographic Characteristics}

Extremes of age in our study were 15 and 65 years with the modal class consisting of the age group above 39 years. It was found in Figure 2 that the male sex was more affected than the female sex with a sex ratio of 9 .

\subsection{Clinical Features}

The men's quarter of the prison was the most affected with the least affected

Table 1. Prevalence of geo-helminthiasis in Kassapa detainees.

\begin{tabular}{cccc}
\hline Variables & Modalities & Prevalence (not \%) & 95\% CI \\
\hline Years & & & \\
& 2017 & 10.2 & {$[7.2 \% ; 14.4 \%]$} \\
2018 & 4.8 & {$[2.5 \% ; 8.9 \%]$} \\
Origin of detainees & 2019 & 2.9 & {$[1.8 \% ; 4.6 \%]$} \\
& (Communes) & & \\
& Annexe & 4.2 & {$[1.5 \% ; 10.6 \%]$} \\
& Kamalondo & 6.0 & {$[3.3 \% ; 10.9 \%]$} \\
& Kampemba & 4.7 & {$[2.4 \% ; 9.2 \%]$} \\
Katuba & 2.0 & {$[0.6 \% ; 6.3 \%]$} \\
Kenya & 3.9 & {$[1.7 \% ; 8.4 \%]$} \\
& Ruashi & 7.1 & {$[3.9 \% ; 12.4 \%]$} \\
& Lubumbashi & 8.2 & {$[2.7 \% ; 11.5 \%]$}
\end{tabular}


being that of minors. It was found that the most cited reason for seeking consultation were complaints of abdominal pain; the stools were soft and brown in most cases. It was also noted that there were little amounts of mucus, blood, and worms in the stools. These results have been outlined in Table 2 .

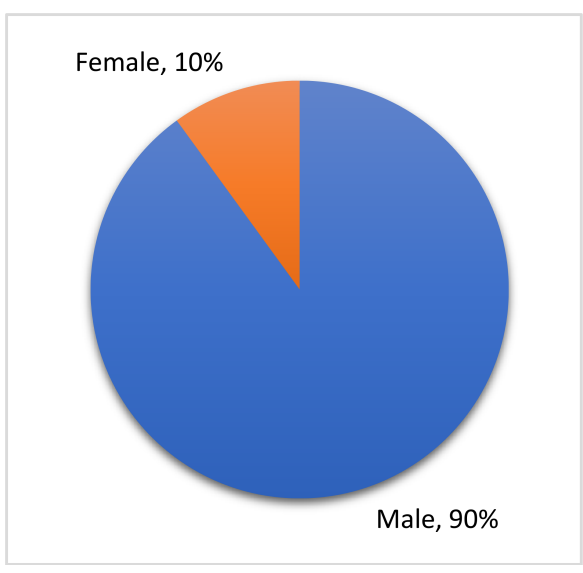

Figure 2. Sociodemographic characteristics.

Table 2. Clinical characteristics of Kassapa prisoners.

\begin{tabular}{|c|c|c|c|}
\hline Variables & Modalities & $\begin{array}{c}\text { Frequencies } \\
(\mathrm{n}=1083)\end{array}$ & $\begin{array}{c}\text { Percentages } \\
\text { (\%) }\end{array}$ \\
\hline \multirow[t]{10}{*}{ Reason for consultation } & Abdominal pain & 273 & 13 \\
\hline & Vomiting & 29 & 25.2 \\
\hline & Pruritus ani & 114 & 2.7 \\
\hline & Anorexia & 64 & 10.5 \\
\hline & Dry cough & 179 & 6 \\
\hline & Diarrhea & 145 & 16.5 \\
\hline & Constipation & 31 & 13.3 \\
\hline & Fever & 29 & 3 \\
\hline & Other & 57 & 2.6 \\
\hline & Association of signs & 162 & 5.2 \\
\hline \multirow[t]{2}{*}{ Macroscopic examination of stool } & Hard & 82 & 15 \\
\hline & Soft & 765 & 7.5 \\
\hline \multirow[t]{3}{*}{ Consistency } & Pasty & 84 & 70.6 \\
\hline & Semi-liquid & 67 & 8 \\
\hline & Liquid & 85 & 6.1 \\
\hline \multirow[t]{3}{*}{ Color } & Yellowish & 292 & 27 \\
\hline & Greenish & 168 & 15.5 \\
\hline & Brownish & 623 & 57.5 \\
\hline \multirow[t]{2}{*}{ Blood } & Yes & 29 & 3 \\
\hline & No & 1054 & 97 \\
\hline \multirow[t]{2}{*}{ Mucus } & Yes & 103 & 10 \\
\hline & No & 980 & 90 \\
\hline \multirow[t]{2}{*}{ Helminths } & Yes & 56 & 5 \\
\hline & No & 1027 & 95 \\
\hline \multirow[t]{2}{*}{ Mucus } & Yes & 59 & 5 \\
\hline & No & 1024 & 95 \\
\hline
\end{tabular}




\subsection{Determinants of Geo-Helminthiasis}

Bivariate analysis showed that there was a statistically significant correlation between gender, treatment and residence area in prison. Thus, taking gender into account, women were by 2.3 (95\% CI [1.3\%; 4.8\%], p value < 0.05 ) more likely to be at risk of suffering from geo-helminthiasis than men, and mebendazole was by 2.1 a better treatment of geo-helminthiasis than albendazole (95\% CI [1.1\%; $4.6 \%$ ], p-value < 0.05). The women's quarter in prison was by 2.7 (95\% CI [1.8\%; $6.5 \%$ ], p-value $<0.05)$ more likely to be at risk than that of the privileged prisoners. These results are presented in Table 3.

By using a downward step-by-step logistic regression and, keeping the other variables constant, and having albendazole as reference, it was found that the treatment with mebendazole showed a statistically significant association (AOR 2.6 (95\% CI [1.2\%; 6.1\%], p-value < 0.05). Compared to the year 2017, the year 2018 showed a statistically significant AOR of 0.20 (95\% CI [0.1\%; 5.1\%], p-value $<0.05)$ ); together with the year 2019 which reported AOR of $0.08(95 \%$ CI $[0 \% ; 2.1 \%]$, p-value $<0.001)$. These results are presented in Table 4.

\subsection{Knowledge and Frequency of Geo-Helminthiasis}

The analysis of comments made by participants in this study shows that the transmission routes for geo-helminthiasis are relatively well known (Figure 3) by these actors who often cite eating dirty food, walking barefoot, dirty water, as evidenced by these quotes:

"Eating dirty food and walking barefoot" Female inmate EID, Kassapa.

“Walking barefoot" Male inmate EID, Kassapa.

"Walking barefoot in the dirty water" Male inmate EID, Kassapa.

Table 3. Determinants of geo-helminthiasis in bivariate analysis.

\begin{tabular}{|c|c|c|c|c|}
\hline \multirow{2}{*}{ Variables } & \multicolumn{2}{|c|}{ Soil-transmitted helminthiasis } & \multirow{2}{*}{ OR95\% CI } & \multirow{2}{*}{$\mathrm{p}$-value } \\
\hline & Present not (\%) & Absent not (\%) & & \\
\hline \multicolumn{5}{|l|}{ Sex } \\
\hline Male & $45(50.4)$ & $930(924.6)$ & & \\
\hline Female & $11(5.6)$ & $97(102.2)$ & $2.3[1.1 \% ; 4.6 \%]$ & $0.016^{\star}$ \\
\hline \multicolumn{5}{|l|}{ Treatments } \\
\hline Albendazole & $43(48.7)$ & $899(893.3)$ & & \\
\hline Mebendazole & $13(7.3)$ & $128(133.7)$ & $2.1[1.1 \% ; 4.6 \%]$ & $0.023^{*}$ \\
\hline \multicolumn{5}{|c|}{ Residence in prison } \\
\hline The privileged & $10(13.1)$ & $244(240.9)$ & & \\
\hline Minors & $4(2.8)$ & $51(52.2)$ & $1.9[0.5 \% ; 6.2 \%]$ & 0.288 \\
\hline Women & $11(5.6)$ & $97(102.4)$ & $2.7[1.8 ; 6.5 \%]$ & $0.025^{*}$ \\
\hline Men & $31(34.4)$ & $635(631.6)$ & $1.1[0.5 ; 2.6 \%]$ & 0.638 \\
\hline
\end{tabular}

OR: Raw Odds Ratio, ${ }^{\star} \mathrm{p}<0.05, \mathrm{CI}$ : Confidence Interval. 
Table 4. Determinants of geo-helminthiasis in multivariate analysis.

\begin{tabular}{cccc}
\hline Variables & AOR & $95 \% \mathrm{CI}$ & p-value \\
\hline Treatments & & & \\
Albendazole & Reference & & \\
Mebendazole & 2.6 & {$[1.2 \% ; 6.1 \%]$} & $0.029^{*}$ \\
Period (3 years) & & & \\
2017 & Reference & & \\
2018 & 0.20 & {$[0.1 \% ; 5.1 \%]$} & $0.003^{*}$ \\
2019 & 0.08 & {$[0 \% ; 2.1 \%]$} & $0.000^{* *}$ \\
\hline
\end{tabular}

Reference $=1$, AOR: Adjusted Odds Ratio, ${ }^{*} \mathrm{p}<0.05,{ }^{* *} \mathrm{p}<0.001$; CI: Confidence Interval.

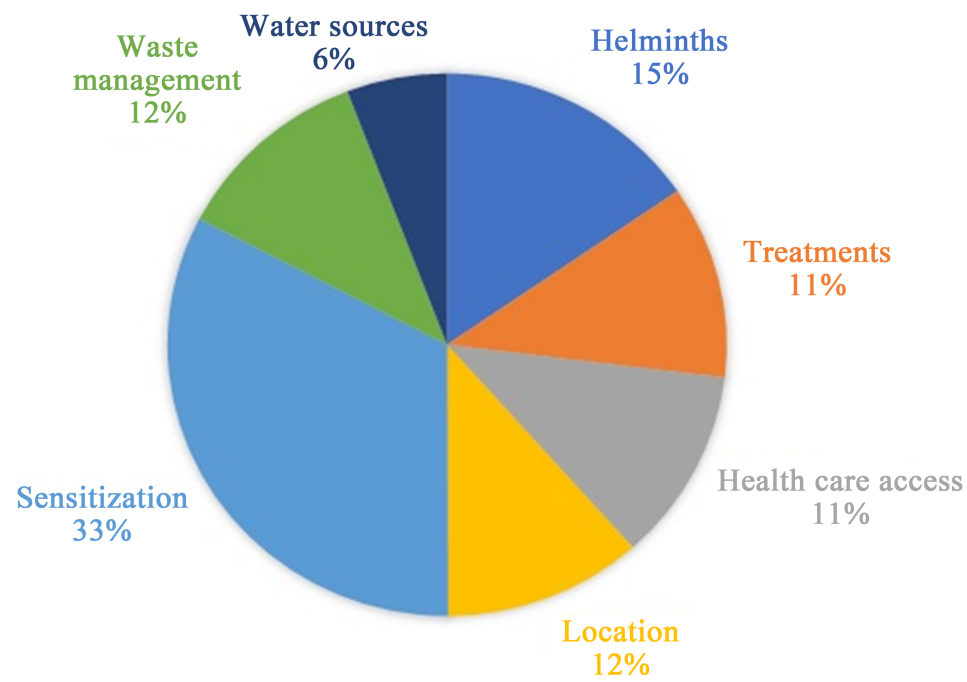

Figure 3. Knowledge of inmates about geo-helminthiasis.

Even if the majority of participants have knowledge about geo-helminthiasis, resources needed to fight this infection remain insufficient. The following quotes relate only to the treatments:

"fairly satisfactory as sometimes we pay for the medicine ourselves" Female inmate EID, Kassapa.

The analysis of comments made by prisoners shows that geo-helminthiases are defined as: worms as the comments below suggest:

"These are worms" Male inmate EID, Kassapa.

However, the analysis of comments on the management of waste as well as water supply among inmates points to the existence in the prison of garbage cans, dump pits, water taps and streams.

"We put waste in the garbage cans and dump pits" as testified by a Male and Female EID detainee, Kassapa.

"We put waste in the garbage can" said a male detainee, Kassapa.

"The prison has taps and running water", reported a male inmate, Kassapa.

"We have taps and water running on a daily basis", states a male inmate, Kas- 
sapa.

Data collected on caregivers about waste management reveals the existence in the prison of garbage cans and an incinerator, as evidenced by this quote:

"We have garbage cans and an incinerator" stated a Male EIPS caregiver, Kassapa.

\subsection{Systematic Screening for Geo-Helminthiasis}

Comments made by detainees indicate that no paraclinical examination was carried out as evidenced by the following quotes:

"No, not the lab, we are only given drugs", a Male EID detainee stated at Kassapa.

Comments by caregivers on treatment and the place where drugs are distributed indicate that worm killers are distributed during the parade or consultation sessions as evidenced by these words:

"We give albendazole and mebendazole", as reported by a Female EIPS nursing staff, Kassapa.

"during the parade and when prisoners are taking their drugs as a result of awareness raising" stated a female EIPS nursing staff, Kassapa.

"Screening is done in every consultation session" said a Male EIPS caregiver, Kassapa.

\subsection{Awareness of Geo-Helminthiasis}

Comments made by healthcare providers mention the following as awareness raising places and messages: during consultation, during the parade, during campaigns, messages are delivered on personal hygiene and food and how to ensure maintenance of water points, as evidenced by this quote:

"We give drugs during campaigns and when ensuring the maintenance of water points" said a Male EIPS caregiver, Kassapa.

"We often do this during the parade, and in consultation sessions by giving information on the disease and hygiene practices", said a Male EIPS caregiver, Kassapa.

"We insist on personal and food hygiene among detainees as hygiene practices are often poorly observed", said a Male EIPS caregiver, Kassapa.

"We must first have the necessary drugs and raise awareness among a reduced number of detainees, increase the number of health education sessions and raise awareness in the blocks", said a Male EIPS caregiver, Kassapa.

\subsection{Knowledge Assessment}

Based on the 2014 EDS DRC Knowledge assessment model [12], we conducted an assessment of knowledge as follows:

- For each element of the assessment, the number of participants who assigned a given score in the corresponding cell was recorded.

- For each element of the assessment, these results are shown in Table 5 and Table 6. 
Table 5. Assessment of the knowledge of the prisoners of Kassapa.

\begin{tabular}{|c|c|c|c|c|c|c|}
\hline \multirow{2}{*}{ Element } & \multirow{2}{*}{$\begin{array}{l}\text { Excellent } \\
\text { (Score: } 4)\end{array}$} & \multirow{2}{*}{$\begin{array}{l}\text { Very good } \\
\text { (Score: } 3 \text { ) }\end{array}$} & \multirow{2}{*}{$\begin{array}{c}\text { Good } \\
\text { (Score: } 2)\end{array}$} & \multirow{2}{*}{$\begin{array}{l}\text { Not good } \\
\text { (Score: } 1)\end{array}$} & \multicolumn{2}{|c|}{$\begin{array}{c}\text { Total score } \\
(\text { Maximum }=84)\end{array}$} \\
\hline & & & & & Number & $\%$ \\
\hline Helminths & 2 & 1 & 0 & 0 & 11 & 13.09 \\
\hline Treatments & 1 & 2 & 0 & 0 & 10 & 11.9 \\
\hline Waste management & 1 & 0 & 2 & 0 & 8 & 9.52 \\
\hline Water sources & 0 & 2 & 1 & 0 & 10 & 11.9 \\
\hline Access to Health care & 0 & 2 & 1 & 0 & 8 & 9.52 \\
\hline Location & 2 & 0 & 1 & 0 & 10 & 11.9 \\
\hline Awareness raising & 1 & 1 & 1 & 0 & 9 & 10.71 \\
\hline
\end{tabular}

The level of knowledge of prisoners rose to $78.54 \%$.

Table 6. Assessment of the knowledge of healthcare providers.

\begin{tabular}{|c|c|c|c|c|c|c|}
\hline \multirow[t]{2}{*}{ Element } & \multirow{2}{*}{$\begin{array}{l}\text { Excellent } \\
\text { (Score: 4) }\end{array}$} & \multirow{2}{*}{$\begin{array}{l}\text { Very good } \\
\text { (Score: } 3 \text { ) }\end{array}$} & \multirow{2}{*}{$\begin{array}{c}\text { Good } \\
\text { (Score: } 2)\end{array}$} & \multirow{2}{*}{$\begin{array}{l}\text { Not good } \\
\text { (Score: } 1 \text { ) }\end{array}$} & \multicolumn{2}{|c|}{$\begin{array}{c}\text { Total score } \\
(\text { Maximum }=84)\end{array}$} \\
\hline & & & & & Number & $\%$ \\
\hline Helminths & 3 & 0 & 0 & 0 & 12 & 14.28 \\
\hline Treatments & 3 & 0 & 0 & 0 & 12 & 14.28 \\
\hline Waste management & 1 & 2 & 0 & 0 & 10 & 11.9 \\
\hline Water sources & 1 & 2 & 0 & 0 & 10 & 11.9 \\
\hline Access to Health care & 2 & 1 & 0 & 0 & 12 & 14.28 \\
\hline Location & 1 & 2 & 0 & 0 & 10 & 11.9 \\
\hline Awareness raising & 3 & 0 & 0 & 0 & 12 & 14.28 \\
\hline
\end{tabular}

The level of knowledge of health care providers rose to $92.82 \%$.

$(4 \times$ number of participants who rated Excellent $)+(3 \times$ number of participants who rated Very good $)+(2 \times$ number of participants who rated Good $)$ $+(1 \times$ number of participants who rated Not good $)$.

- The maximum score was equal to 7 (elements of assessment) $\times 4$ (excellent score) $\times$ number of participants.

\section{Discussion}

\subsection{Sociodemographic Characteristics}

Our study found that the age above 39 was the modal class with $29.4 \%$ followed by the age group ranging between 25 and 32 with $28.1 \%$. The least affected age group was that of minors with $6.3 \%$. We might assume that our results conflict with those of Kamariza. 39.5\% fell within the age group of $15-35$ years as the class of minors enjoy areas with improved sanitation; $60 \%$ was in the age group of 36 years and above; the age group of 36 years and above was the most widely represented [13]. In 2013 in Burundi, Nyabenda B. studied the knowledge, atti- 
tudes and practices of the population of Buterere municipality with respect to the fight against geo-helminthiases and found that $58.7 \%$ of respondents fell in the age group of 15 and 34 years, $41.2 \%$ were in that of 35 years and above [13]. Our results could be accounted for by the fact that prisoners in the age group above 39 did not only benefit from education campaigns that were conducted but were also beneficiaries of assistance from the health self-help associations, as a result this group was not targeted by campaigns which had been organized. The findings of our study have shown that the male sex was more affected (90\%) than the female sex (10\%) with a sex ratio of 9 men to one woman. Gomido et al. [14] reported $39.8 \%$ of women against $60.2 \%$ of men. Ndagijimana in 2014 in Burundi, found that the female sex was predominantly represented with $54.9 \%$ as against $45.1 \%$ for the male sex [14]. The reason for such female sex predominance could be accounted for by the fact that, based on the general population and housing census which was conducted in 2008, the Burundian female population was predominantly higher $(52.25 \%)$ than the male population $(47.75 \%)$. [14]. The findings of our study may support the claim that male prisoners are more actively involved in handling water than girls and therefore boys are more exposed to parasites. On the other hand, female subjects (IPS $=15.68 \%$ ) are more parasitized than male subjects (IPS $=12.76 \%$ ). Similar results were reported in the far north region of Cameroon where female subjects also presented a low prevalence because girls seem to respect basic hygiene rules more than boys. [15]. Findings by Angela F et al. [16] in 2001, do not attribute this difference to the susceptibility of the hosts to the parasites. This would rather be explained by a rapid acquisition of the parasite by the boys; moreover these would carry more adult female worms [16].

\subsection{Prevalence of Geo-Helminthiasis}

The general prevalence of geo-helminthiasis for 3 years is $17.9 \%$, i.e., $10.2 \%$ (2017); 4.8\% (2918) and 2.9\% (2019) annually. This prevalence is lower than that found in a study in the city of Lubumbashi $16.59 \%$ in 2016; 16.25\% in 2015 and $15.50 \%$ in 2013 [17]. Gomido et al. [14] in a study conducted in 2019 in Benin found a lower prevalence than that of our study, i.e. $6.42 \%$. WHO published a study in 2012 after the last Beninese survey in 2009 and found an overall prevalence of 5.2\%. Mugono M. et al. [14] in 2014 in Tanzania found that the prevalence was $6.73 \%$. Wang et al. [14] 2012 found $47.1 \%$ while Gabriel et al. [14] obtained $81 \%$. The difference between the prevalence rates that we report in our study could be explained by the impact of the annual systematic deworming campaigns organized by the Ministry of Public Health in the DRC, mainly targeting children under the age of 5 and inmates in Kassapa prison by distributing mebendazole through the MTN program [18].

\subsection{Determinants of Geo-Helminthiasis}

Bivariate analysis shows that there is a statistically significant association be- 
tween: gender, treatment and prison residence. The descending stepwise logistic regression and, keeping the other variables constant, the mebendazole-based treatment and the period (3 years) are statistically significant. The MTN program via UNICEF have also approved that mebendazole remains a good dewormer in the fight against geo-helminthiasis [18]. Indeed, many authors have found the absence of hand washing before meals and after the toilet as important risk factors for geo-helminthiasis. [6] [13] [14]. It is therefore crucial to develop and stimulate the systematic reflex of washing hands with soap and water in the general population, children and especially in detainees in particular.

\subsection{Knowledge about Geo-Helminthiasis}

Our study shows that the transmission routes for geo helminthiases are relatively well known among the prisoners who often mention eating dirty food, walking barefoot, dirty water, but resources to fight the infection remain insufficient as only the treatments were mentioned in the respondent comments. The analysis of comments by caregivers on waste management points to the existence of garbage cans and an incinerator. These findings are similar to those reported by Elouard $\mathrm{Y}$ and those documented in a report that was produced in 2014 in $\mathrm{Bu}$ rundi, which found that the population washed their hands before eating at more than $89 \%$, followed by domestic work [13] [19]. However, just over a quarter of the population reported washing their hands after having a bowel movement. Other times cited include before going to bed, getting up and going to mass [13] [19]. Sonego IL. and Mosler in their study on behavior related to water, hygiene and family sanitation in Burundi, found that the vast majority of respondents said that they wash their hands before eating (93\%), more than half after eating (60.6\%) and (56.8\%) before preparing the meal [13]. Togola OB and, Sidibe Y. found the same observation respectively on the modes of contamination of geo-helminthiases [13]. This could be explained by the fact that the prison population is educated on parasitoses with telluric transmission. Hence in the control measures, scaling up education messages on wearing shoes, adopting hygiene practices related to water among detainees would reduce the occurrence of geo-helminthiasis.

\subsection{Awareness and Systematic Screening of Geo-Helminthiasis}

Health education reveals that water is considered potable if it comes from: taps installed inside or outside the home; public fountains or taps; wells/boreholes equipped with pumps; protected dug wells and protected springs [8].

Our study therefore has the merit of revealing that in this environment, the Congolese state gives products during the campaigns and it ensures maintenance of water points., education is often done through parades, consultation sessions in which information is provided on the disease and hygiene practices. There is a need to acquire the necessary drugs and conduct awareness sessions with a reduced number of detainees, scale up health education sessions and raise aware- 
ness in the blocks. Focus should be placed on ensuring body and food hygiene among detainees as hygiene practices are often poorly observed as stated by male nursing staff (EIPS/Kassapa). Medical care [18] and the place of distribution of the drugs, in the comments made by the nursing staff show that mebendazole is provided as treatment during parades or consultation sessions. Screening is done in every consultation session as reported by a male EIPS caregiver, Kassapa. Our observation corroborates findings in Ofa's studies on the effect of deworming which gave interesting results [1] [18]. Even after two rounds of treatment, the prevalence of helminthiasis had fallen by $44 \%$ and there had been a dramatic reduction in the intensity of the infection [1] [18] [20].

\section{Study Limitations}

Our study was carried out using primary data from a cross-sectional survey. As a result, we can only establish an association between the occurrence of geo-helminthiasis in the prisoners of Kassapa in Lubumbashi in the DRC and various explanatory variables, but cannot show a causal relation between the occurrence of the infection and various factors used. Regarding the qualitative approach, the data resulting from this survey are essentially based on declarative responses which heavily rely on the sincerity of respondents. In addition, helminth types as variable were not collected during the survey; therefore, we were not able to assess the types of worms that could be linked to the occurrence of geo-helminthiasis.

These limitations aside, study results appear to be representative. We believe that selection bias probably did not affect our results due to the high response rate during collection which was $99 \%$. However, the methodology and the quality of the data allowed us to obtain fairly reliable information on the suggestion of etiological hypotheses on geo-helminthiasis. These results will contribute to a better understanding of the determinants of the occurrence of geo-helminthiasis and the establishment of promising strategies to strengthen neglected tropical disease (NTD) programs in the DRC.

\section{Conclusion}

The annual prevalence of geo-helminthiasis remains broadly high in this prison. This result may reflect poor hygiene, insufficient health education exposing therefore, detainees to the risk of geo-helminthiasis. The male sex is the most affected. Gender, treatment, prison residence and year have a statistically significant association. Poor hygienic conditions are cited by detainees as a mode of contamination of geo-helminthiasis. The vulnerability of detainees appeared to be more linked to the poor Water Sanitation and Hygiene (WASH) and their status as prisoners. Nevertheless, good awareness of transmission routes, water supply, knowledge on the access to healthcare, waste management remain critical. Thus, guaranteeing an inclusive approach to the needs of prisoners, and a gender-based global approach, which would take into account fundamental hu- 
man rights, is appropriate in the control of these diseases.

\section{Acknowledgements}

We would like to thank the entire editorial team who participated in this study and supported it at the publication level. Special thanks go to Professor ERIC Mukomena Sompwe for designing this study. We do also appreciate the great support of Doctor Lenge who is the head of Kassapa Health Centre and all his team for field support.

\section{Contributions from the Authors}

Design of the study and tools: ANK, AAK, NM, KG, implementation and supervision: EMS, TM, analysis and interpretation: EMS, PMC, ANK, CK, AAK, manuscript: all. All the authors have read.

\section{Ethical Approval and Consent to Participate}

Ethics approval was obtained from the University of Lubumbashi and the Ethics Committee of the Faculty of Medicine, University of Lubumbashi, DRC (BP 1825). All participants provided written informed consent prior to participating.

\section{Conflicts of Interest}

The authors declare no conflicts of interest regarding the publication of this paper.

\section{References}

[1] WHO (2004) Schistosomiasis and Geo-Helminthiasis: Prevention and Control. Report of a WHO Expert Committee, Geneva, No. 912, 68.

[2] Mulumba, M.P., Ntumpa, M.M. and Muhindo, M.H. (2009) Estimation of the Prevalence of Geo-Helminths in Kinshasa (Meta-Analysis of 185 Studies). African Annals of Medicine, No. 2, 4.

[3] UNHCR (2004) Human Rights and Prisons: A Human Rights Training Manual for Prison Staff. United Nations, New York and Geneva, No. 11, 261.

[4] WHO (2000) World Water Supply and Sanitation Situation Assessment Report. 80.

[5] Royal Society of Tropical Medicine and Hygiene (2000) Transactions of the Royal Society for Tropical Medicine and Hygiene. Tropical Medicine, 91, 31-36.

[6] CDC-Centers for Disease Control and Prevent (2019) CDC-Soil-Transmitted Helminths, April.

[7] Lorenzo, S. and Denis, D. (2013) Acting Faster to Reduce the Global Impact of Neglected Tropical Diseases-A Roadmap for Implementation. 15.

[8] DRC, Ministry of Public Health (2015) National Health Development Plan 2011-2015. MSP, Kinshasa, 98: 21.

[9] Campbell, S.J., Savage, G.B., Gray, D.J., Atkinson, J.-A.M., Soares Magalhães, R.J., Nery, S.V., et al. (2014) Water, Sanitation and Hygiene (WASH): An Essential Component for the Sustainable Control of Helminths and Schistosomiasis Transmitted by the Soil. PLOS Neglected Tropical Diseases, 8, 2651. 
https://doi.org/10.1371/journal.pntd.0002651

[10] Dao, M.M. (2016) Knowledge, Attitudes and Practices of Children Aged 10 to 15 Facing Schistosomiasis in the Rural Commune of Kalaban Coro, Kati Circle (Mali). January, 87.

[11] Mboko, A.I. (2019) Health System of the Democratic Republic of Congo-Kinshasa School of Public Health. March, 24.

[12] Ministry of Planning and Monitoring of the Implementation of the Revolution of Modernity (MPSMRM), Ministry of Public Health (MSP) and ICF International (2014) Demographic and Health Survey in the Democratic Republic of Congo. Rockville, September 30 2014, 696

[13] Kamariza, M. (2015) Study of Factors Contributing to the Persistence of Geo-Helminthiasis in Rural Areas: Case of Kirundo Province. Cross-Sectional Study for Analytical Purposes, Louvain Cooperation. Burundi, August 2015, 88.

[14] Gomido, I., Bachirou, Z., Amoukpo, H., et al. (2019) Socio-Demographic and Behavioral Factors Associated with Geo-Helminthiasis. Benin, October 2019, 119.

[15] Dankoni, et al. (2015) Epidemiological Survey on Schistosomiasis Caused by Schistosoma haematobium and Schistosoma mansoni in Primary Schools in the Sub-Division of Taïbong-Dziguilao, Far-North Region Cameroon. Journal of Applied Biosciences, 90, 8397-8407. https://doi.org/10.4314/jab.v90i1.10

[16] Angela, F., José-Guillermo, E., René, A. and Santiago, M.C. (2001) Soil-Transmitted Helminth Infections at Very High Altitude in Bolivia. Transactions of the Royal Society of Tropical Medicine and Hygiene, 3, 272-277. https://doi.org/10.1016/S0035-9203(01)90232-9

[17] André, N.K., Philippe, M.C., Luboya, N.O. and Eric, M.S. (2018) About Mebendazole Deworming Blankets in Children under Five (2011-2016) and the Incidence Rate of Helminthiasis in the Kamalondo Health Zone, in DR Congo: Interrupt or Continue the Strategy? International Journal of Recent Scientific Research, 9, 23596-23600.

[18] UNICEF-WHO (2007) How to Add Deworming to Vitamin A Distribution. 42.

[19] Elouard, Y. (2015) Report of the Baseline Study Carried Out in the Commune of Marangara, WASH (Water, Hygiene and Sanitation) Sectoral Group in Emergency Burundi. August, 14.

[20] WHO (2020) Soil-Transmitted Helminthiasis Newsletter for March 2.

\section{Abbreviations}

$\begin{array}{ll}\text { EID } & \text { Individual Interview of Detainees } \\ \text { EIPS } & \text { Individual Interview of Nursing Staff } \\ \text { IPS } & \text { Simple Parasitaemia Index } \\ \text { NTD } & \text { Neglected Tropical Diseases } \\ \text { WHO } & \text { World Health Organization } \\ \text { QDA } & \text { Qualitative Data Analysis } \\ \text { DRC } & \text { Democratic Republic of Congo } \\ \text { UNICEF } & \text { United Nations Children's Fund }\end{array}$




\section{Appendices}

\section{Annex 1: Survey Questionnaire}

Title: Determinants and Knowledge on geo-helminthiasis in inmates of Kassapa prison in Lubumbashi in DRC

SERIES A: CLINICAL INFORMATION

Name: Gender: Age: Origin:

1. REASONS FOR CONSULTATIONS:
Abdominal pain
Diarrhea
Vomiting $\square$
Constipation

Anal pruritus

Fever

Anorexia

Dry cough

Other;

2. PARACLINIC ELEMENTS :

- Macroscopic examination

Color: $\quad$ Yellow $\square$ Greenish $\square \quad$ Brownish

Consistency: Hard $\square \quad$ Soft $\square \quad$ Pasty $\square \quad$ Semi-liquid $\square \quad$ Liquid $\square$

Presence:

$\begin{array}{lllll}\text { - blood: } & \text { Yes } \square & \text { No } \square & \text { - worms: Yes } \square & \text { No } \square \\ \text { - mucus: } & \text { Yes } \square & \text { No } \square & \text { - mucus: Yes } \square & \text { No } \square\end{array}$

- Microscopic examination:

Direct examination: Yes $\square \quad$ No

Culture: $\quad$ Yes $\square \quad$ No $\square$

- Biology:

$\mathrm{Hb}$ $\mathrm{GB}:$

FL:

3. HELMINTHIC SPECIES :

Trichuristrichiura Ascaris lumbricoides $\square$

Ankylostoma duodenale $\square$

Necator americanus

Strongyloides stercoralis

4. TREATMENT:

Albendazole $\square \quad$ Levamisole $\square$ Mebendazole $\square \quad$ Piperazine

Others:

\section{Annex 2: Interview Guide}

TITLE: DETERMINANTS AND KNOWLEDGE ON

GEO-HELMINTHIASIS AMONG PRISON DETAINEES FROM KASSAPA TO LUBUMBASHI IN DRC

Information note

As part of our research study in medicine, we will carry out a study in the municipality of Lubumbashi from September 21 to October 15, 2020 on the prevalence and knowledge about geo helminthiases among inmates in the Kassapa prison environment in Lubumbashi in the DRC. The main goal of this study will be to analyze the knowledge in prisoners regarding geo-helminthiasis; this will make it possible to better adapt deworming promotion strategies in favor of detainees.

Your participation in this study is of the utmost importance to us. You can 
also be assured of the confidentiality of the information we collect.

Name of interviewer:

Number:

Date:

\section{GENERAL INFORMATION}

1. Age

2. Gender

3. Education level

4. Marital status

5. Membership of a social group or club

II. THEME 1: Knowledge about geo-helminthiasis

-Sub-themes 1.1: Water sources

-Sub-themes 1.2: Waste management

-Level 1.2.1: trash cans

-Level 1.2.2: Burned in the yard

-Level 1.2. 3: Incinerated

III. THEME 2: Knowledge of systematic screening against geohelminths

-Sub-themes 2.1: Treatments

-Sub-themes 2.2: Access to healthcare

-Level 2.2.1: medical products

-Level 2.2.2: Motivations and appreciations

IV. THEME 3: Knowledge of hygiene and sanitation practices

-Sub-themes 3.1: Practices in terms of awareness raising

-Level 3.1.1: Health education

-Level 3.1.2: Personal hygiene

\section{A. INDIVIDUAL INTERVIEW WITH CARE STAFF}

(Total number of nursing staff to be interviewed: 3 )

Nursing staff (names, age, occupation)

1. What is meant by geohelminths?

$\mathrm{R} /$

2. Can you name some helminths that you know?

$\mathrm{R} /$

3. What has the Congolese state done to fight geo-helminthiasis?

$\mathrm{R} /$

4. Where do you think the systematic screening against geohelminths is carried out in your health center?

$\mathrm{R} /$

5. What are the health rights of detained persons?

$\mathrm{R} /$

6. Why raise awareness of hygiene and sanitation among detainees?

$\mathrm{R} /$ 
7. What does the message on the fight against geo helminthiases consist of during your awareness raising?

$\mathrm{R} /$

8. What do you think are the difficulties in getting awareness messages across?

$\mathrm{R} /$

9. What products do you give for routine screening of prisoners?

$\mathrm{R} /$

10. How often is geo-helminth screening done in prisoners in a year?

$\mathrm{R} /$

11. In your opinion, what can be done to ensure that awareness-raising activities target more the needs of detainees?

$\mathrm{R} /$

12. According to you, between a detained person and a non-detained person, which one has more risk in the face of geo-helminthiasis?

$\mathrm{R} /$

13. Can you tell us how waste is managed within your structure?

$\mathrm{R} /$

14. In your opinion, what should be done to facilitate access to care for detained persons?

$\mathrm{R} /$

Name of interviewer:

Number:

Date:

\section{GENERAL INFORMATION}

1. Age

2. Gender

3. Education level

4. Marital status

5. Membership of a social group or club

II. THEME 1: Knowledge of sanitary facilities

-Sub-themes 1.1: Water sources

-Sub-themes 1.2: Waste management

-Level 1.2.1: trash cans

-Level 1.2.2: Burned in the yard

-Level 1.2. 3: Incinerated

III. THEME 2: Knowledge of systematic screening against geohelminths

-Sub-themes 2.1: Treatments

-Sub-themes 2.2: Access to healthcare

-Level 2.2.1: medical products

-Level 2.2.2: Motivations and appreciations

IV. THEME 3: Knowledge of hygiene and sanitation practices

-Sub-themes 3.1: Practices in terms of awareness raising

-Level 3.1.1: Health education

-Level 3.1.2: Personal hygiene 


\section{B. INDIVIDUAL INTERVIEW WITH PRISONERS}

( Total number of prisoners to be interviewed: $3 \mathrm{~b}$ )

Prisoners (Names, age, occupation)

1. What is meant by geohelminths?

$\mathrm{R} /$

2. Can you name some helminths that you know?

$\mathrm{R} /$

3. What are the risky behaviors or habits in the face of geo-helminthiasis?

$\mathrm{R} /$

4. In your opinion, where should we go to be screened for geo-helminthiasis?

$\mathrm{R} /$

5. Among you prisoners, has anyone been hospitalized after being diagnosed with geo-helminthiasis?

$\mathrm{R} /$

6. What are the difficulties encountered in accessing healthcare?

$\mathrm{R} /$

7. How do you rate access to health services in Kassapa?

$\mathrm{R} /$

8. Are you satisfied with the service provided?

$\mathrm{R} /$

9. What do you say about health workers?

$\mathrm{R} /$

10. How do the health workers welcome you?

$\mathrm{R} /$

11. Has any of your fellow prisoners been the victim of marginalization?

$\mathrm{R} /$

12. According to you, between a detained person and a non-detained person, which one has more risk in the face of geo-helminthiasis?

$\mathrm{R} /$

13. Can you tell us how waste is managed within the prison?

$\mathrm{R} /$

14. How do you think you go about recharging your batteries with water in the prison?

$\mathrm{R} /$ 